Open Access

\title{
Error compensation in high-speed milling of deep cavity dies and molds based on the lengthened shrink-fit holder
}

\author{
Zhou Houming*, Liu Bo, Zhou Youhang and Peng Ruitao
}

\begin{abstract}
Background: In high speed milling of the dies and molds characterized by large-scale and deep cavities with the lengthened shrink-fit holder (LSFH), the machining error caused by the tool deflection is not allowed to be ignored.

Methods: The deformation of the LSFH and cutting tool are predicted, and at the same time the machining error caused by this deformation are predicted too based on the milling force prediction model and the finite element model. Taking into account the complex mutual coupling between milling force and the deformation, an error compensation method is proposed based on a balancing iterative algorithm.

Results: The compensation tool path is obtained and the off-line machining error compensation is achieved. Milling example shows that the machining error after compensation less $77.4 \%$ than that of no compensation.

Conclusions: The results demonstrate that the proposed error compensation method is reasonable and can greatly reduce the machining error.
\end{abstract}

Keywords: Dies and molds; LSFH; High-speed milling; Error compensation

\section{Background}

Nowadays, high-speed machining (HSM) technology is widely used in die and mold processing (López de Lacalle et al. 2006), how to select or design a suitable cutting tool according to the characteristics of workpiece is a key to improve efficiency and quality, optimize machining parameters, and reduce processing costs. Traditionally, the stiffness of the shank-chuck-tool system is so limited, whereas the semi-finishing and finishing machining of the dies and molds characterized by large-scale and deep cavity still mainly depends on electrical discharge machining (EDM) and manual polishing which will result in low efficiency and poor quality and cannot meet the needs of an increasingly competitive market.

As a new cutting tool hold technology, lengthened shrink-fit holder (LSFH) has drawn tremendous industrial attention recently. For touching workpiece in high-speed

\footnotetext{
* Correspondence: zhouhouming@xtu.edu.cn

School of Mechanical Engineering, Xiangtan University, Xiangtan 411105, People's Republic of China
}

\section{至 Springer}

(c) 2015 Houming et al. This is an Open Access article distributed under the terms of the Creative Commons Attribution License (http://creativecommons.org/licenses/by/4.0), which permits unrestricted use, distribution, and reproduction in any medium provided the original work is properly credited. machining of dies and molds characterized by large-scale and deep cavity, LSFH is more suitable than those traditional hold systems such as the collet chuck and the static pressure expansive chuck because of its simple structure, high balance accuracy, and high clamping strength (Zhou et al. 2012; Tony and Schmitz 2007; Zhang 2006).

Several works had been carried out to investigate the stiffness and defection of the cutting tool system which will affect the machining precision and surface quality (Salgado et al. 2005). Some scholars focus on the estimation of the geometrical accuracy in multi-axis milling process (Lamikiz et al. 2008) and the topography prediction of ball-end milled surfaces, considering the tool parallel axis offset (Arizmendi et al. 2008). However, the deformation of the matching of LSFH and cutting tool is particularly prominent during the machining process due to the special lengthening structure of LSHF. Therefore, how to reduce the machining errors caused by this deformation is very important to make full use of the 
advantages of LSFH, ensure the machining quality, and improve the machining efficiency.

The intention of this work is to offline compensate the machining errors caused by the deformation of the matching of LSFH and cutting tool system in 3-Axis $\mathrm{CNC}$ finishing milling the dies and molds characterized by large-scale and deep cavity. Taking into account the complex and mutual coupled relationship between the milling force and the deformation, the iterative methods are used to obtain the compensated cutting tool path and achieved the offline errors compensation. The rationality of the error compensation method was verified with an actual processing example.

\section{Methods}

\section{Machining error analysis}

As shown in Fig. 1, the machining error is usually defined as the normal distance between the nominal machined surface and the actual machined surfaces. Machining error is divided into static error and cutting state error according to whether the error related to the cutting states. The error that has nothing to do with the processing status is called static error, such as the machine geometric and transmission errors and the tool wear and manufacturing errors. Cutting state error occurs in the cutting process, and this error is usually caused by the deformations (which usually root in the cutting force and cutting heat) of machine, cutting tools, and workpiece system.

Due to using the high-speed machining centers, the machine has a high-precision of manufacturing and a highperformance closed-loop control system (Zhang and Pan 1997; Zhang et al. 2002). So the machining error generated by the static error of the machine occupies a small proportion of the whole machining error during highspeed milling of the dies and molds characterized by large-scale and deep cavity based on the LSFH. For the static errors caused by the cutting tool, the high- performance and high-speed machining centers generally have automatic compensation for the cutting tool length and diameter which can eliminate the impact of machining errors. When a machine processes dies and molds characterized by large-scale and deep cavity, the workpieces have big volume and good rigidity, its stiffness is far greater than that of the cutting tool system. Therefore, the deformation of the matching of LSFH and the cutting tool system has become the main reason to cause the machining errors.

\section{Lengthened shrink-fit holder}

The LSFH is a clamping component between the shank and cutting tool, and there are no additional parts when the cutting tool is clamped. The LSFH is pulled to shank by a thread drawbar that is fixed in a shank which will create a taper interference fit connection between the shank and LSFH. The clamping part of the LSFH is heated up to $250-425{ }^{\circ} \mathrm{C}$ in a short time. When the inner undersize diameter of LSFH expands over to the diameter of the cutting tool, the cutting tool is inserted into the LSFH at once. As the LSFH cools down, a reliable and high-precision hold is produced due to the interference between the LSFH and the cutting tool. The picture of the headstock, shank, LSFH, and cutting tool system is shown in Fig. 2.

The simplified structure diagram of LSFH is shown in Fig. 3. The material of LSFH is a high strength alloy steel with a large thermal expansion coefficient.

\section{Machining errors caused by the deformation}

When using a ball-end cutting tool in CNC surface finishing, the first thing to do is to disperse the nominal designed workpiece surface into a series of cutting tool position points along a certain cutting direction, and then connect the cutting tool position point to generate the cutting tool path. The cutting tool cuts the workpiece along the cutting tool path, and then the machining surface will be obtained. In the cutting process, the

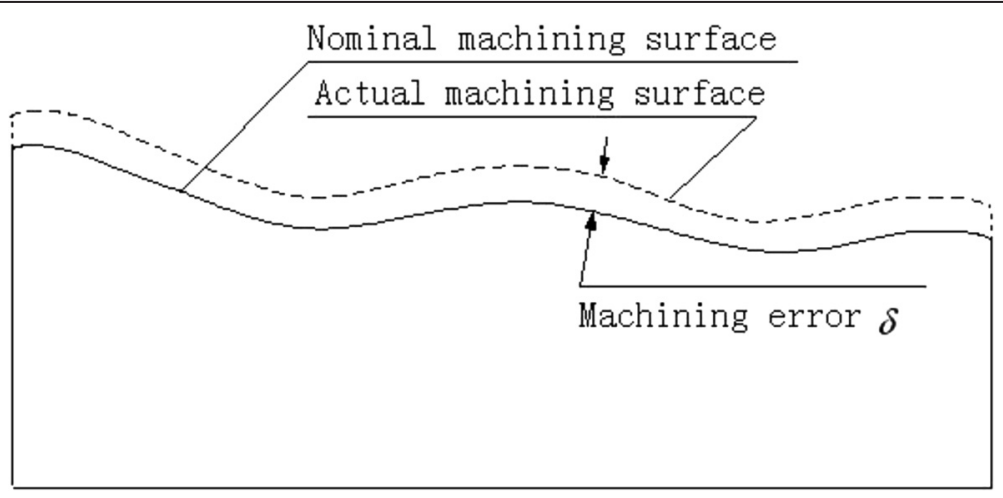

Fig. 1 Schematic diagram of the machining error 


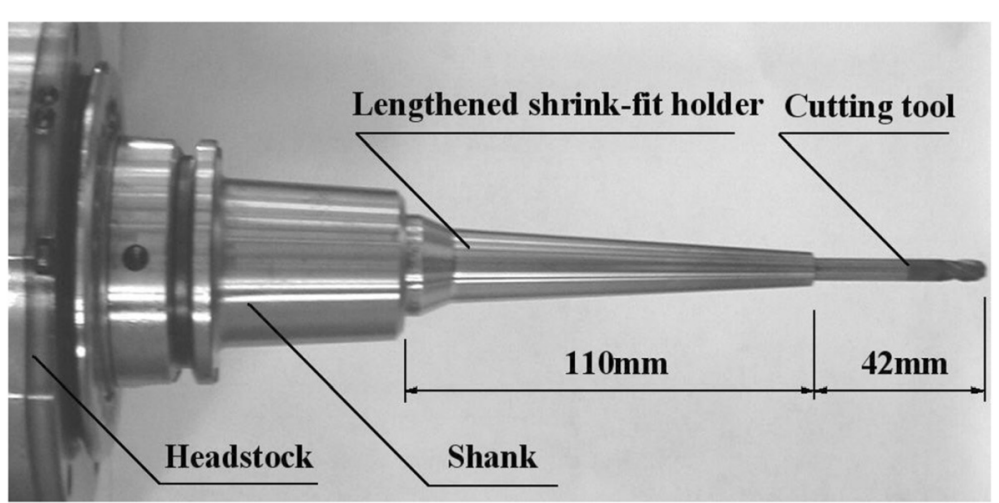

Fig. 2 Picture of the shank, LSFH, and cutting tool system

theoretical contact points of the cutting tool and workpiece are called the nominal contact points. When the ball-end cutting tool is simplified as a half sphere and the cutting thickness is ignored, the nominal contact point is achieved as shown in Fig. 4. Where $c$ is the nominal contact point, $N$ is the normal of the nominal workpiece surface at contact point $c, \varphi$ is the angle between cutting tool axis and $N$, and $f$ is the feed direction of the cutting tool.

In an actual machining process, due to the deformation, the actual contact point of the cutting tool and workpiece does not coincide with the nominal contact point which will result in the machining errors. In order to determine the relationship between the deformation of the cutting tool and machining error at the nominal contact point $c$, the cutting force and deformation diagram in the plane determined by $N$ and cutting tool axis is shown in Fig. 5. Since the axial stiffness of the matching of LSFH and cutting tool is much larger than its radial stiffness, only the horizontal component of the cutting force is taken into account in this analysis, where $L$ is the overhang length of the matching of LSFH and cutting tool, $c^{\prime}$ is the actual contact point of the cutting tool and workpiece, $F$ is the horizontal component of the cutting force, $\rho$ is the radius of curvature of the surface at the point $c, e$ is the horizontal radial deformation of the cutting tool, and $\delta$ is the machining error. Generally, the surface of dies and molds is smooth and the deformation is very small. Then has $o c^{\prime} \approx \rho+\delta$, and therefore:

$$
\begin{aligned}
(\rho+\delta)^{2}= & e^{2}+\left(L-\sqrt{L^{2}-e^{2}}\right)^{2}+\rho^{2}-2 \rho \sqrt{e^{2}+\left(L-\sqrt{L^{2}-e^{2}}\right)^{2}} \\
& \times \cos \left[\pi+\phi-\tan ^{-1}\left(\frac{e}{L-\sqrt{L^{2}-e^{2}}}\right)\right]
\end{aligned}
$$

Due to the horizontal radial displacement $e$ much less than the overhang length $L$, the above Eq. (1) can be simplified as:

$$
(\rho+\delta)^{2} \approx e^{2}+\rho^{2}+2 \rho e \sin \varphi
$$

Thus machining error $\delta$ can be expressed as:

$$
\delta \approx \sqrt{e^{2}+\rho^{2}+2 \rho e \sin \varphi-\rho}
$$

Define the horizontal direction's deformation sensitive coefficient $S$ in nominal contact point $c$ of the matching of LSFH and cutting tool as the partial differential of the machining error $\delta$ to horizontal radial deformation (Law and Geddam 2003; Lim and Meng 1995):

$$
S=\frac{\partial \delta}{\partial e}=\frac{(e+\rho \sin \varphi)}{\sqrt{e^{2}+\rho^{2}+2 \rho e \sin \varphi-\rho}}
$$

For the dies and molds characterized by large-scale and deep cavity, the radius of curvature $\rho$ is usually far greater than the horizontal radial displacement of the cutting tool which caused by cutting force. So the above Eq. (4) can be simplified as:

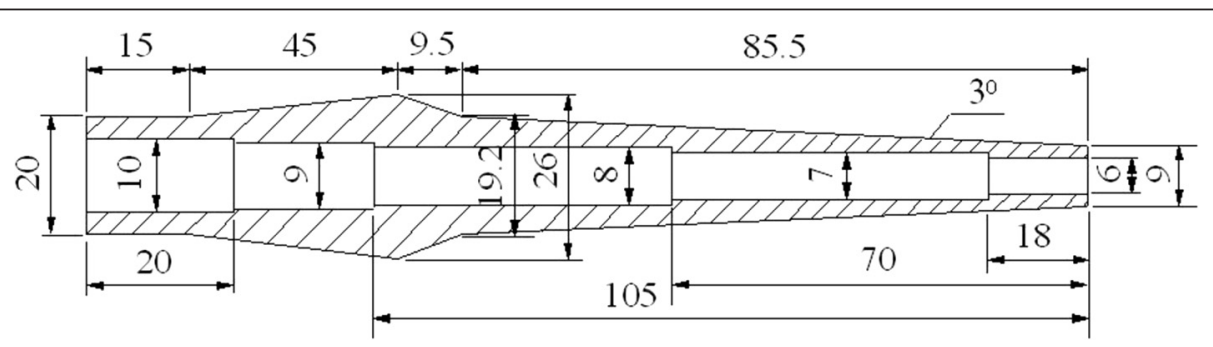

Fig. 3 Simplified structure diagram of LSFH 


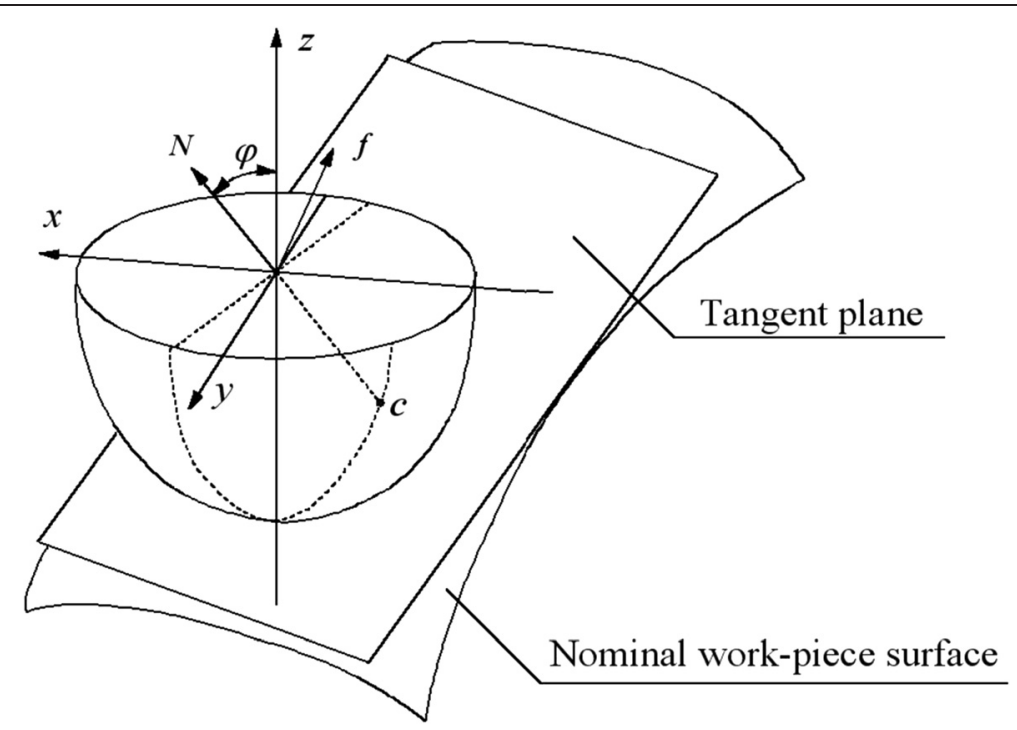

Fig. 4 Nominal contact point of the surface machining

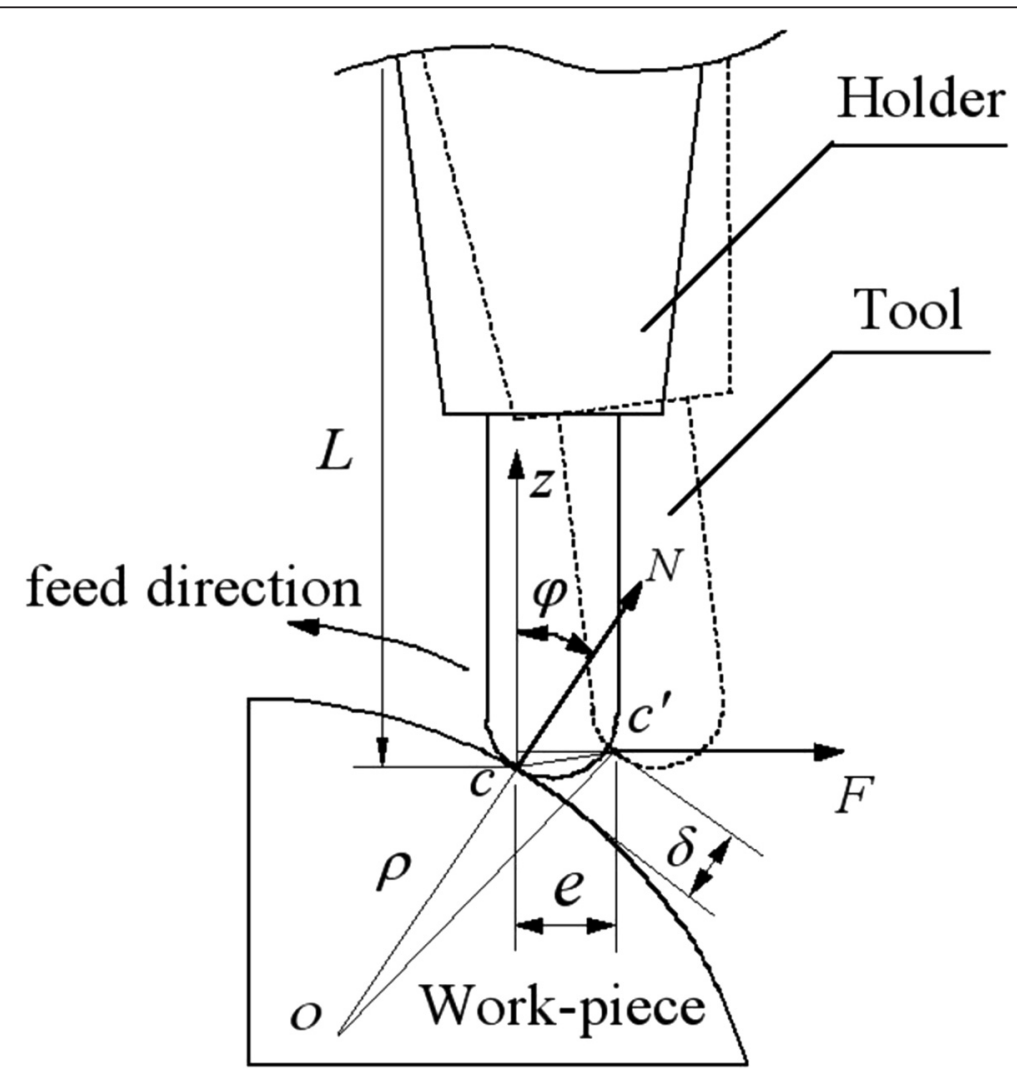

Fig. 5 Relationship between tool deformation and errors 

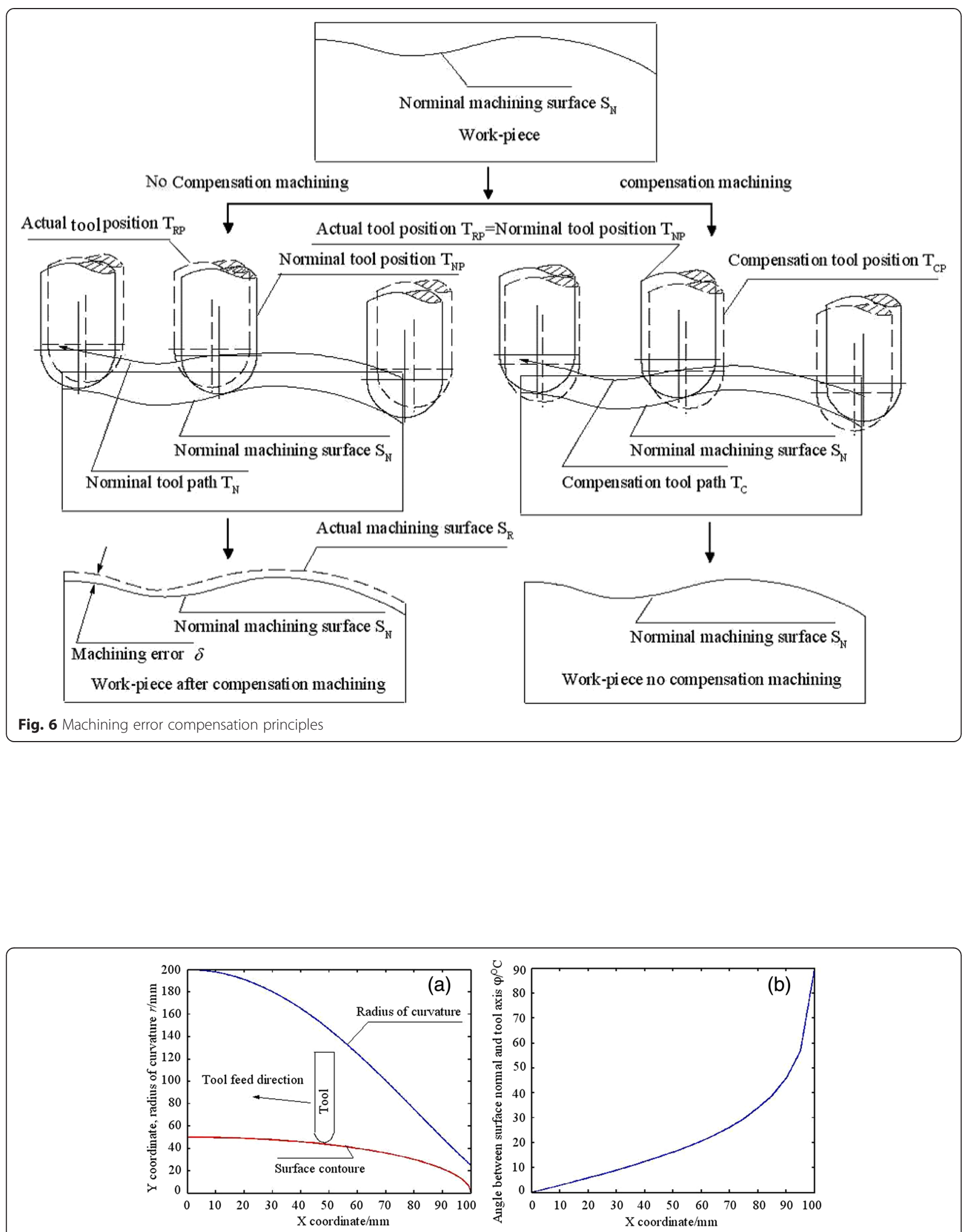

Fig. 7 An example for the workpiece surface analysis; a the radius of curvature distribution along the machining surface and $\mathbf{b}$ the angle between the surface normal and tool axis 


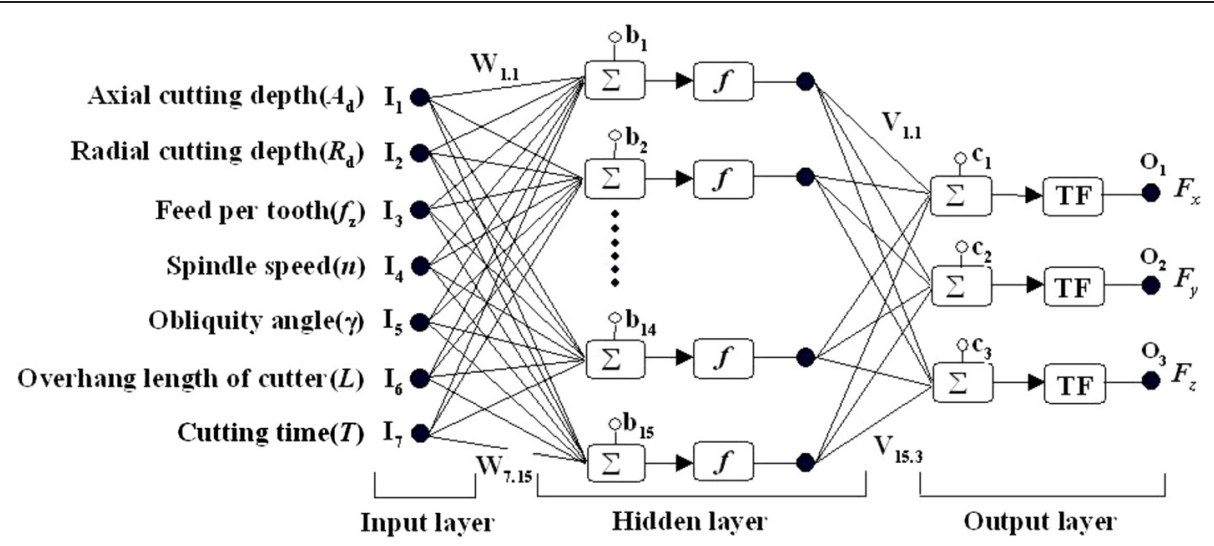

Fig. 8 Network topology structure of the milling force model

$S \approx \sin \varphi$

Then, the final machining error in the nominal contact point $c$ can be expressed as:

$$
\delta=S \cdot e \approx e \cdot \sin \varphi
$$

It can be found that the final machining error can be obtained through determining the radial deformation and the angle $\varphi$. The literature (Ryu et al. 2003) suggests that without considering the influence of cutting edge to the generation process of the machining surface and directly predicting the forming errors from the deformation of the cutting tool is faster than that of the time simulation about 300 times.

\section{Results and discussions}

\section{Error compensation}

According to the above analysis, the machining error compensation procedure mainly includes four aspects. Firstly, analyzing the workpiece surface feature to determine the nominal cutting tool path; secondly, using an appropriate milling force model to predict the milling force; thirdly, building a proper deformation model of the matching of LSFH and cutting tool to predict the machining error; and finally, correcting the cutting tool path to achieve the error compensation. A machining error compensation principle is shown in Fig. 6. CAM is used to program the NC machining procedure to get the nominal tool path $T_{N}$. If both the cutting tool and the workpiece have a rigid body, then the nominal machined surface $S_{N}$ is the expected machined surface without causing machining errors. But in the actual machining process, due to the cutting force, the matching of LSFH and cutting tool deformed and made the actual tool path $T_{N}$ deviated, so that the actual machined surface $S_{R}$ deviate from the nominal surface $S_{N}$ and result in the machining errors. Through predicting the deformation of the matching of LSFH and cutting tool, the machining error caused by this deformation can be predicted. Then, the compensation cutting tool path $T_{C}$ can be obtained by correcting the $T_{N}$ in opposite direction of the machining error. Thereby, the actual machined workpiece surface coincides with the $S_{N}$ theoretically and the machining deformation errors can be eliminated.

\section{Machining surface analysis}

First of all, according to the characteristics of the workpiece surface, to determine the way of feeding and nominal cutting tool path, on this basis, a nominal cutting tool path will be divided into nominal cutting tool position points and then analyzes the radius of curvature of the workpiece surface as well as the angle between the normal of workpiece surface and the cutting tool axis at each nominal cutting tool position point to provide the input conditions for the milling force model and the basis for the calculation of machining error. In two-dimensional ellipse surfaces, for example, Fig. 7 shows the simulation result of the surface characteristics using Matlab. In this example, the ellipse long axis is $100 \mathrm{~mm}$ and short axis is $50 \mathrm{~mm}$ and the coordinate origin at the center of the elliptical. Cutting tool feed direction and the radius of curvature $\rho$ along the workpiece surface is shown in Fig. 7a. It can be found that $\rho$ has a maximum of $200 \mathrm{~mm}$ when $x$ is 0 ; as $x$ increases, $\rho$ decreases, and $\rho$ has a minimum of $25 \mathrm{~mm}$ when $x$ is 100. The tendency of the angle $\varphi$ is shown in Fig. 7b. It shows that $\varphi$ has a minimum $0^{\circ}$ when $x$ is 0 ; as $x$

Table 1 Physical characteristic of LSFH and cutting tool

\begin{tabular}{lccc}
\hline & $\begin{array}{l}\text { Young's modulus, } \\
E\left(10^{5} \mathrm{MPa}\right)\end{array}$ & $\begin{array}{l}\text { Poisson's } \\
\text { ratio, } \mu\end{array}$ & $\begin{array}{c}\text { Density, } \\
\rho\left(10^{3} \mathrm{~kg} / \mathrm{m}^{3}\right)\end{array}$ \\
\hline $\begin{array}{l}\text { Lengthened shrink-fit } \\
\text { holder }\end{array}$ & 2.0 & 0.3 & 7.8 \\
Cutting tool & 6.4 & 0.22 & 15 \\
\hline
\end{tabular}




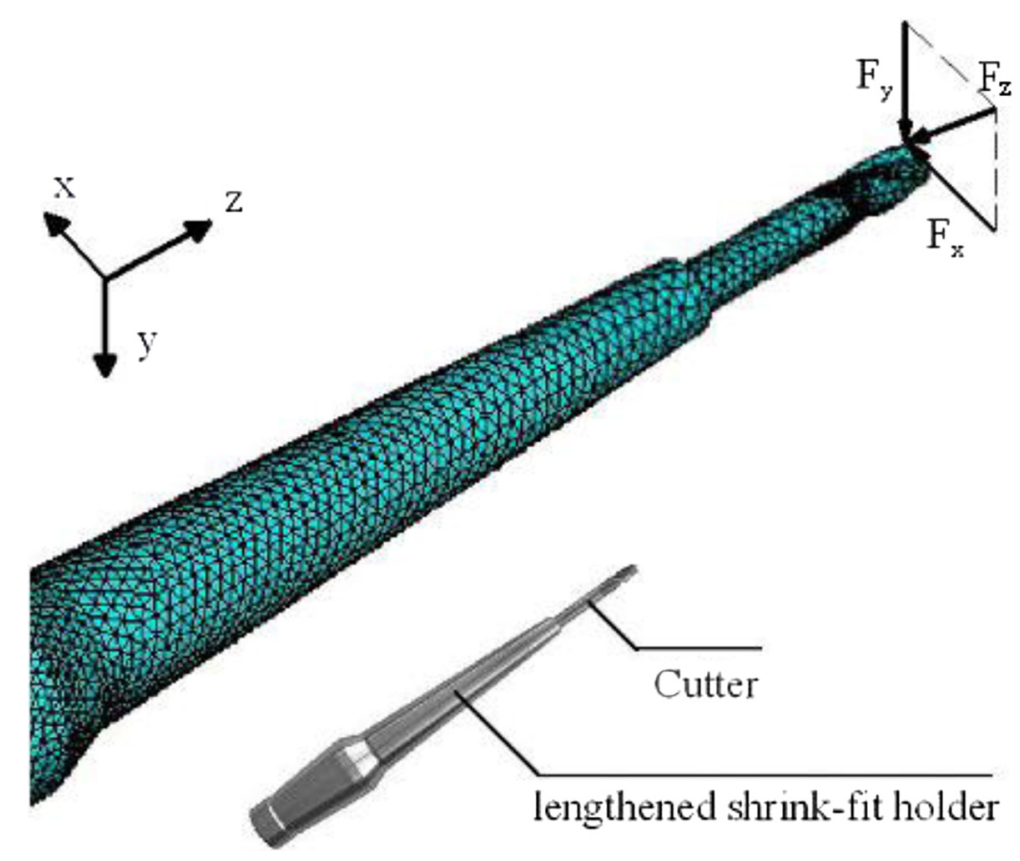

Fig. 9 Finite element models and force diagram

increases, $\varphi$ increases, and $\varphi$ has a maximum of $90^{\circ}$ when $x$ is 100 .

\section{Milling force model}

Owing to the complexities of the milling process and the special structure of the match of LSFH and cutting tool, it is difficult to establish an analytical milling force model which is consistent with the actual processing conditions. A milling force model based on BP neural network is used in this paper (Zhou et al. 2010). The network topology structure of this milling force model is shown in Fig. 8, where $I$ and $O$ represent the input and output of the network, respectively; $W$ represents the connection weight between input layer and hidden layer; $V$ represents the connection weight between hidden layer and output layer; $b$ and $c$ represent the valve of hidden layer and output layer, respectively; and $f$ and TF are the transfer functions of hidden layer and output layer, respectively. Each transient milling force can be calculated under the given machining conditions and parameters. In the milling process, static and periodic changes of dynamic milling force work on the cutting tool and workpiece. Static force makes the cutting tool

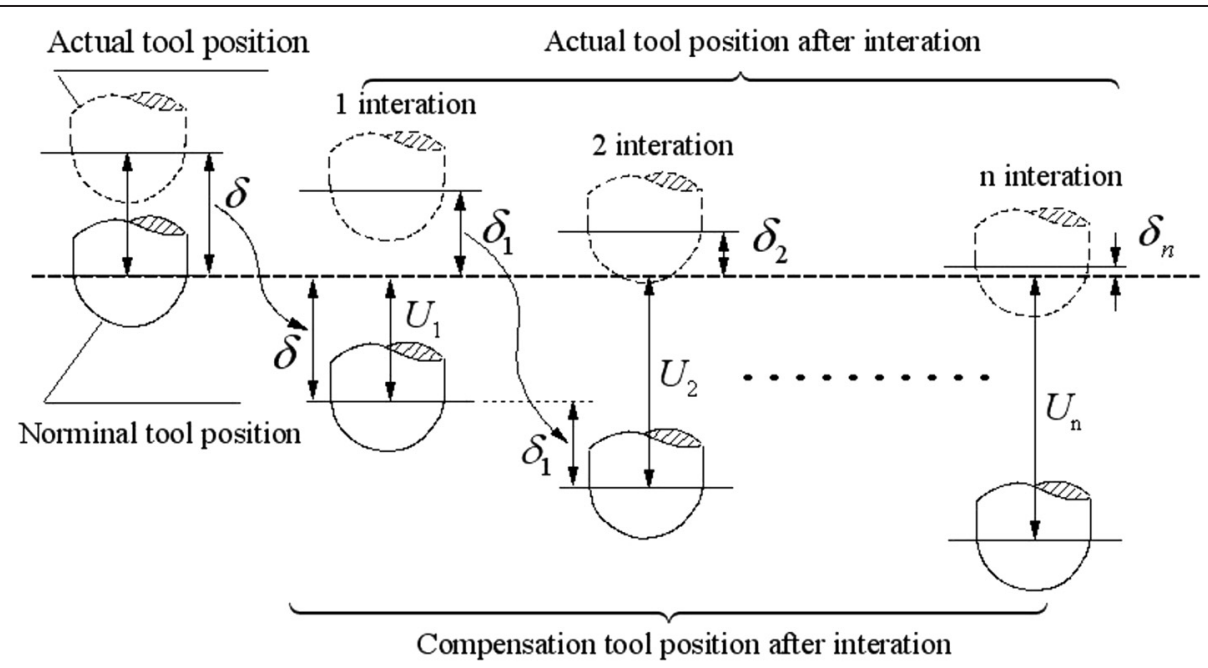

Fig. 10 Schematic diagram of the iterative algorithm of tool position point 


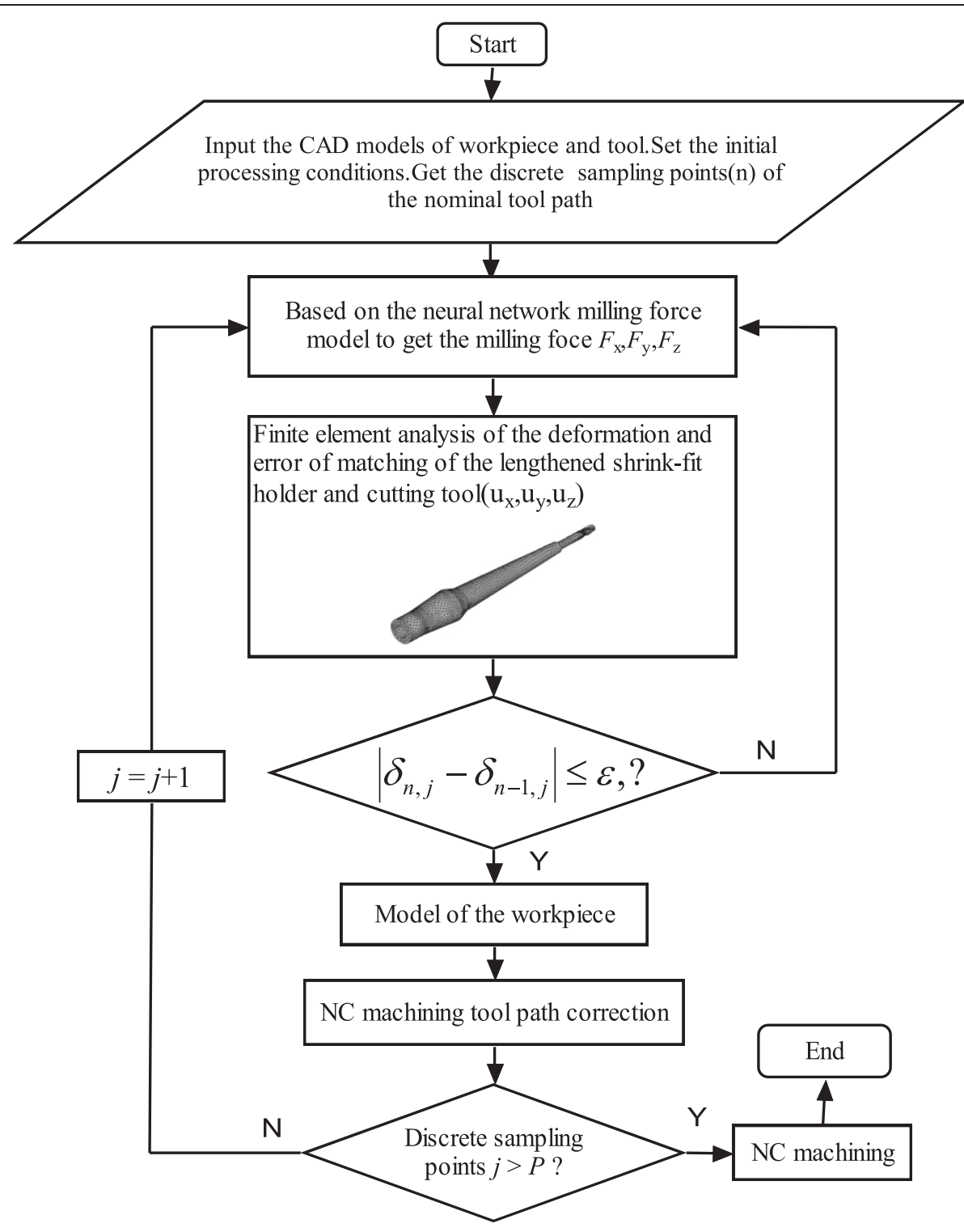

Fig. 11 Flowchart of the offline error compensation

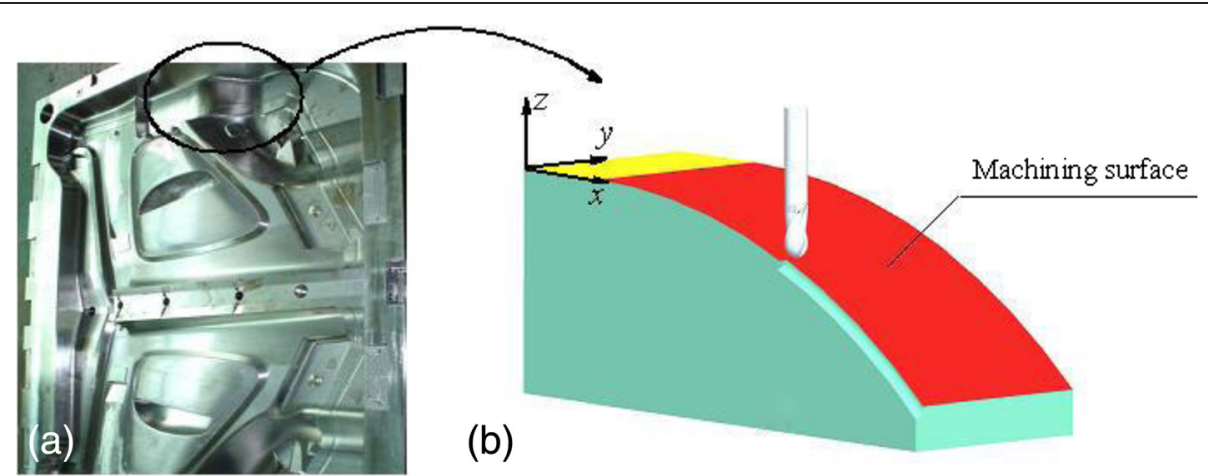

Fig. 12 Actual mold and the extractive local machining feature. a Car doors injection mold. b Extractive local machining feature 


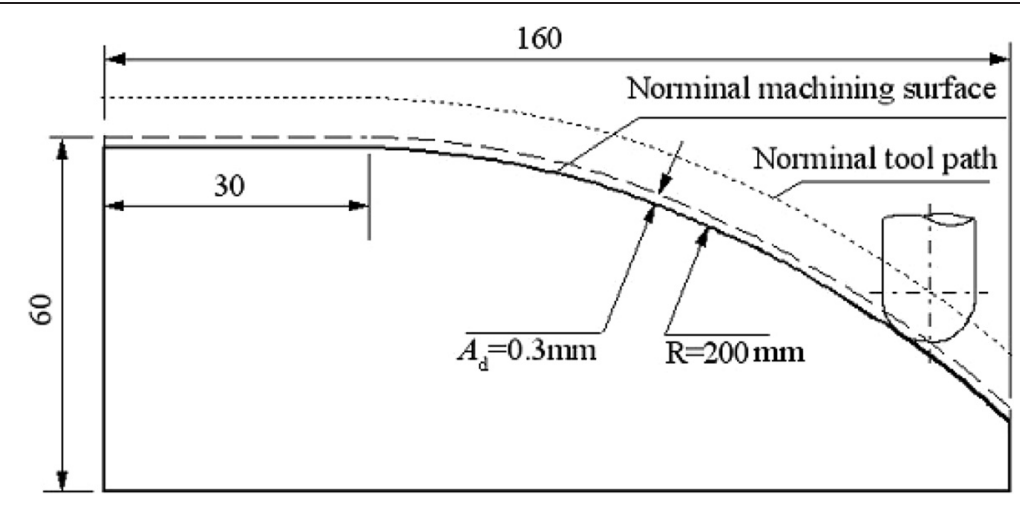

Fig. 13 Section profile size of the workpiece surface

and the workpiece produce static deformations which will result in the size error of the workpiece. Dynamic milling force will worsen the surface quality of the workpiece. Therefore, the deformation of the workpiece mainly matters with the static force. In this paper, the average milling force is used to predict the machining error.

\section{Deformation model of the matching of LSFH and cutting tool}

The accuracy of the deformation prediction of the matching of LSFH and cutting tool under the milling force will directly affect the prediction accuracy of machining error. In this work, the finite element method is used to predict the deformation so that the predicted result is closer to the actual machining conditions. The software is ANSYS12.0, and the influence of non-linear contact is considered in the established finite element model. Input conditions of the model are the milling force predicted in milling force model. The material properties of LSFH and cutting tool are listed in Table 1.

The finite element model and the force diagram are shown in Fig. 9. The solid element is solid 185 used in this FEA model. The contact elements Targe170 and Conta174 are used to simulate the rigid target surface of the cutting tool and the flexible contact surface of LSFH, respectively. In this model, the total elements including contact elements are 18,740. The boundary conditions such as the nodes' displacements $x, y$, and $z$ of the taper surface of LSFH, where it gets connected with the shank, are constrained. In order to save the computing resources and to mesh conveniently without affecting the accuracy of analysis, the solid model is simplified as: 1) the screw thread structure, chamfer, and fillet of the LSFH are neglected (refer to Fig. 3); 2) the friction model between the LSFH and cutting tool is simplified as Coulomb law of friction and the friction coefficient is set to be 0.2 (Frederic et al. 2009).

\section{Machining error compensation process}

According to the above compensation principle, a key of the machining error compensation is to obtain the compensated cutting tool path $T_{C}$; however, the key to obtain $T_{C}$ is to determine each cutting tool compensation position $T_{C P}$. In the milling process, the milling force and the deformation of the matching of LSFH and cutting tool are coupled. On the one hand, cutting force makes the matching of LSFH and cutting tool to deform; on the other hand, the deformation also changes the effective cutting depth and cutting width which will affect the milling force. In order to solve the complex dependencies between the milling force and deformation to get the cutting tool compensation path $T_{C}$, the iterative method can be used to obtain the milling forces and deformation at each cutting tool position point in an equilibrium state. The influences of the deformation on milling force are mainly initiated by changing the actual cutting depth and cutting width. If $A_{d}$ is the nominal cutting depth, then the uncompensated machining error

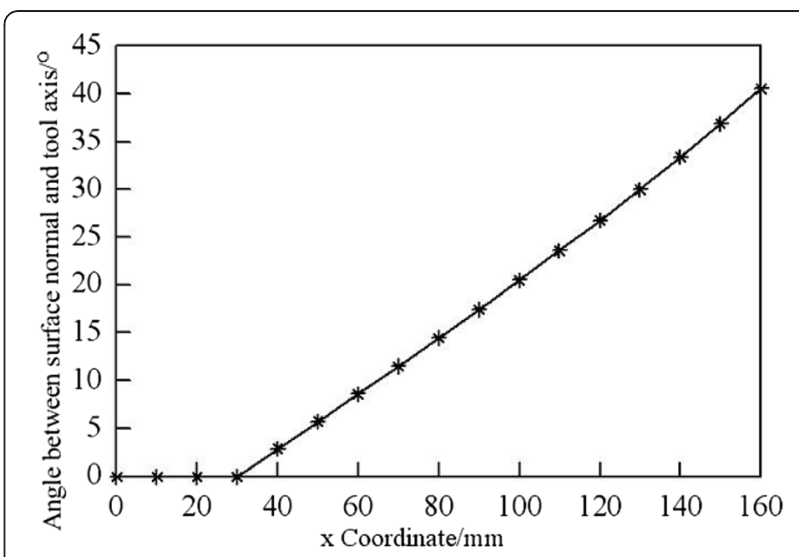

Fig. 14 Angle between workpiece surface normal and cutting tool axis 
Table 2 The predicted milling force and actual cut depth after iteration

\begin{tabular}{|c|c|c|c|c|c|c|c|c|c|c|c|c|c|c|c|c|c|c|c|}
\hline Sample poin & & & 1 & 2 & 3 & 4 & 5 & 6 & 7 & 8 & 9 & 10 & 11 & 12 & 13 & 14 & 15 & 16 & 17 \\
\hline \multirow{6}{*}{ Mill force/N } & \multirow{3}{*}{$\begin{array}{l}\text { Before } \\
\text { iteration }\end{array}$} & $F_{x}$ & 17.82 & 17.82 & 17.82 & 17.82 & 17.87 & 17.92 & 18.35 & 18.71 & 19.41 & 19.83 & 20.44 & 21.15 & 21.93 & 22.36 & 22.97 & 23.78 & 24.13 \\
\hline & & $F_{y}$ & 23.90 & 23.90 & 23.90 & 23.90 & 24.21 & 24.73 & 25.11 & 25.64 & 25.85 & 26.35 & 26.94 & 27.67 & 28.57 & 29.73 & 30.18 & 31.25 & 32.35 \\
\hline & & $F_{z}$ & -14.58 & -14.58 & -14.58 & -14.58 & -14.59 & -14.62 & -14.68 & -15.13 & -15.54 & -15.79 & -16.24 & -16.95 & -17.33 & -17.98 & -18.35 & -18.92 & -19.37 \\
\hline & \multirow{3}{*}{$\begin{array}{l}\text { After } \\
\text { iteration }\end{array}$} & $F_{x}$ & 17.82 & 17.82 & 17.82 & 17.82 & 18.76 & 19.01 & 19.75 & 20.26 & 21.28 & 21.77 & 22.69 & 23.33 & 24.34 & 25.04 & 26.0 & 27.16 & 27.95 \\
\hline & & $F_{y}$ & 23.90 & 23.90 & 23.90 & 23.90 & 25.42 & 26.26 & 26.92 & 27.64 & 28.25 & 28.96 & 29.63 & 30.51 & 31.85 & 33.42 & 34.29 & 35.70 & 37.07 \\
\hline & & $F_{z}$ & -14.58 & -14.58 & -14.58 & -14.58 & -15.38 & -15.53 & -15.75 & -16.39 & -16.95 & -17.31 & -17.86 & -18.71 & -19.27 & -20.13 & -20.8 & -21.69 & -22.30 \\
\hline$U_{n} / \mathrm{mm}$ & & & 0.3 & 0.3 & 0.3 & 0.3 & 0.3076 & 0.3081 & 0.3085 & 0.3114 & 0.3130 & 0.3147 & 0.3170 & 0.3191 & 0.3212 & 0.3238 & 0.3259 & 0.3287 & 0.3315 \\
\hline
\end{tabular}


changes the actual cutting depth of the nominal cutting tool position point into $A_{d^{-}} \delta$ and sets the deformation of the cutting tool in the radial feed direction which is $e y$ and the nominal cutting width which is $R_{d}$, so then the actual cutting width becomes $R_{d}$-ey. However, surface machining error is affected mainly by cutting depth, so the ultimate goal of an iterative solution can be converted to solve the actual cutting depth $U_{n}$ at each nominal cutting tool position point, so that the actual cutting tool position coincides with the nominal cutting tool position or meets the given convergence conditions. Iteration process of each cutting tool position point is shown in Fig. 10.

Here, the nominal cutting tool position is the programmed position which does not consider the deformation, and the actual cutting tool position is the deformed cutting tool position. The actual cutting depth in first iteration is the nominal cutting depth plus machining error which did not consider the deformation. Then input the changed cutting depth and other milling parameters into the aforementioned milling force model to predict the milling force again, and then enter the milling force to the finite element deformation model to obtain the new deformation and machining errors. The actual cut depth in the next iteration is the actual cutting depth plus machining errors in the previous iteration, and recalculates the milling force, tool deformation, and machining errors. In an iterative process, machining error in any two successive iterations $n$ and $n-1$ converges to the set error limit $\varepsilon$ namely:

$$
\Delta \delta=\left|\delta_{n}-\delta_{n-1}\right| \leq \varepsilon
$$

Then the iteration is terminated. Set the nominal tool position point vector without considering deformation is
$\vec{X}_{d}$, and then the actual tool position point vector $\vec{X}_{s}$ after the iteration is:

$$
\vec{X}_{s}=\vec{X}_{d}+\vec{U}_{n}
$$

Nominal cutting tool path $T_{N}$ will be sampled by a certain discrete degree $p$, according to the above iteration method to solve all sampling points to get the compensated cutting tool path $T_{C}$. Figure 11 is a flowchart of the offline error compensation, where $\delta_{n j}$ is the machining error of the $j$ th sample points of the nominal cutting tool path after the $n$th iteration step.

\section{Machining error compensation example}

A local surface feature of an injection mold of a car door was extracted to the actual processing (Fig. 12). Machining results of compensation and no compensation are compared to verify the effectiveness and practicality of the above machining deformation error compensation method. The experiments are carried out on a high-speed machining center DMU 60T with maximum rotation speed 24,000 rpm. The workpiece is a mold steel P20 with hardness HRC 30-35 after quenching and tempering. The allowance $t$ needed to be removed in finishing machining is $0.3 \mathrm{~mm}$.

The analysis shows that the workpiece surface to be machined consists of flat and circular surfaces. The contour size of the nominal machined surface $S_{N}$, machining requirements, and the nominal tool path $T_{N}$ are shown in Fig. 13. The width of the workpiece is $55 \mathrm{~mm}$. For the convenience of tool setting in machining and measurement after machining, the workpiece coordinate system is taken as shown in Fig. 12.

The angle $\varphi$ between the normal of machining workpiece surface and the cutting tool axis is shown in Fig. 14.

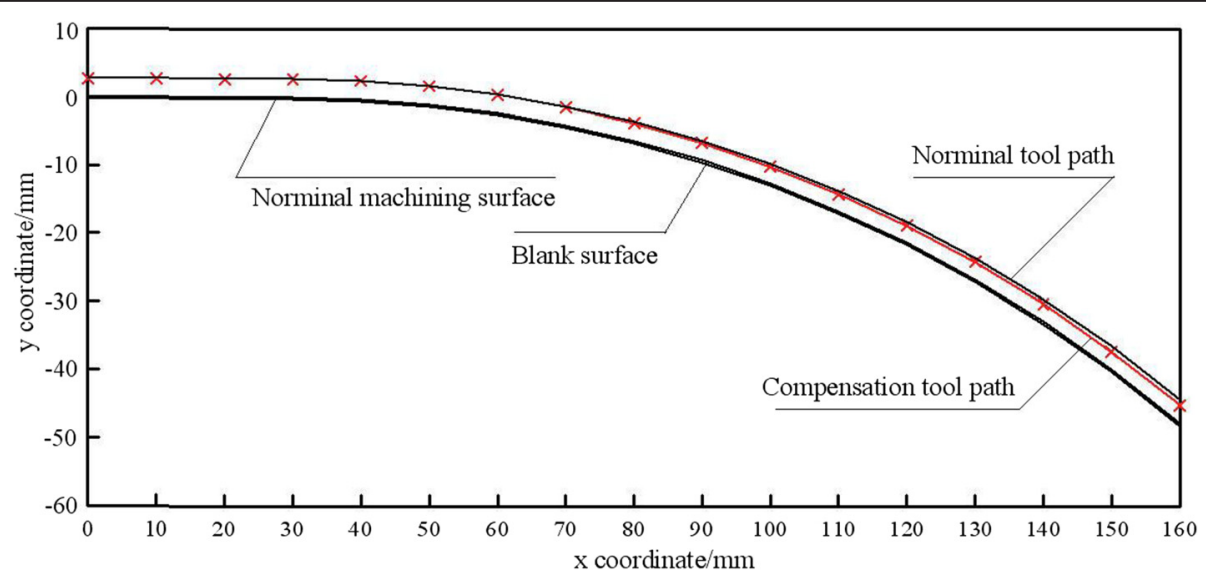

Fig. 15 Predication result of the compensation tool path 


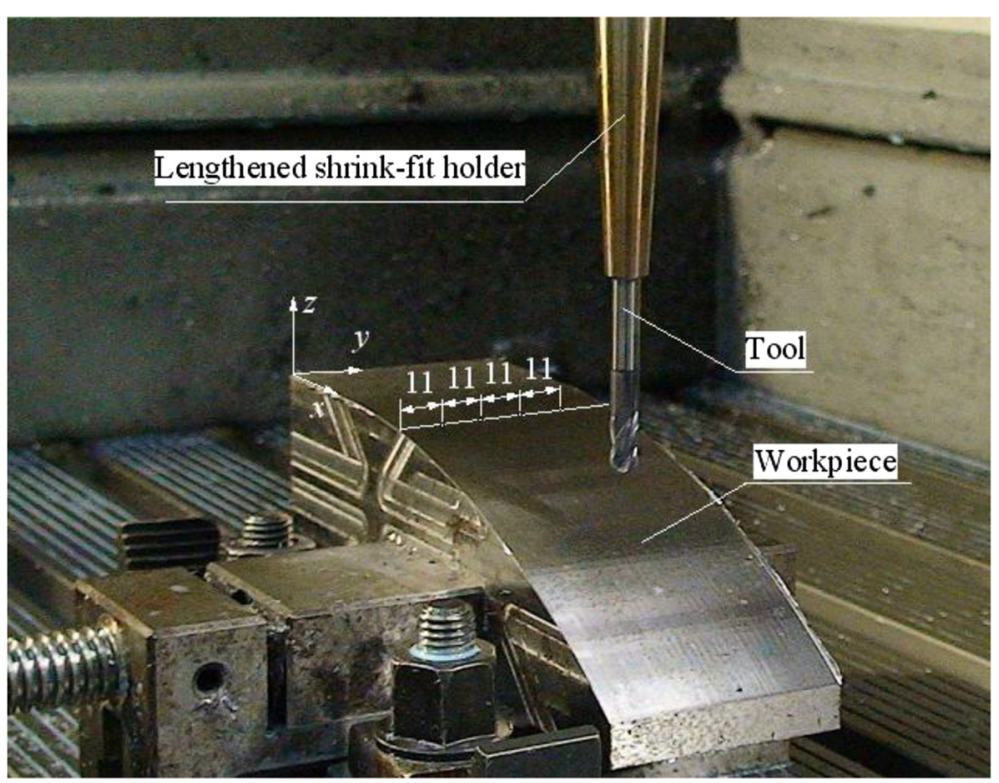

Fig. 16 Workpiece after compensation machining and the arrangements of measuring point

Milling parameters used in compensation processing example are as follows: spindle speed is $16,000 \mathrm{rpm}$, feed per tooth is $0.045 \mathrm{~mm} / \mathrm{z}$, nominal cutting depth is $0.3 \mathrm{~mm}$, and radial cut depth is $0.4 \mathrm{~mm}$. A contouring climb milling is taken in this example.

Samples of the nominal tool paths $T_{N}$ along the machining $\mathrm{x}$ axis (see Fig. 12) every $10 \mathrm{~mm}$ and 17 sampling points are obtained. The error convergence limit $\varepsilon$ is set to 0.01 . Using the aforementioned milling force model and iterative methods, the milling force of each sampling point before iteration and after the iteration and the actual cutting depth $U_{n}$ after the iterative convergence are obtained as shown in Table 2 , where $n=1,2,3, \ldots, 17$ is the number of sampling points.

The compensation tool path is shown in Fig. 15 based on the results of above calculation, under the workpiece coordinate system as shown in Fig. 12. It can be found that in the flat segment of the machining workpiece surface, the nominal tool path coincides with compensated tool path according to Eq. (6) and the compensated tool path deviates from the nominal tool path more and more when the angle $\varphi$ between the normal of the machining workpiece surface and cutting tool axis is increasing. The maximum offset is $0.81 \mathrm{~mm}$ when the

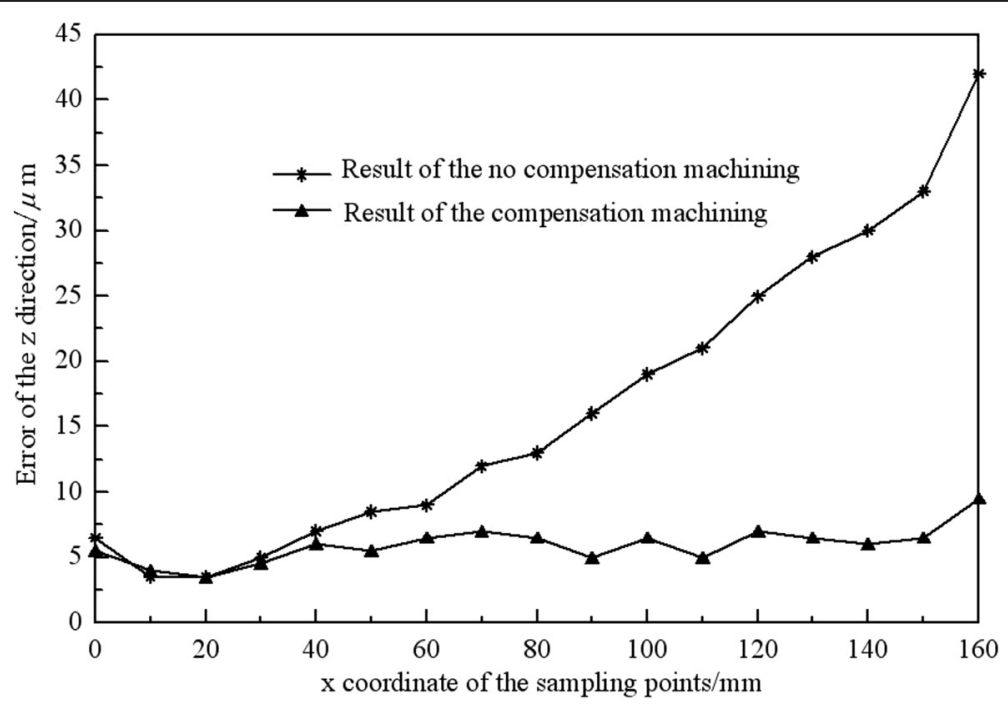

Fig. 17 Comparison of machining errors with compensation and no compensation 
angle $\varphi$ has a maximum value 40.5 when $x=160$. According to the compensated tool path to complete the $\mathrm{NC}$ program for processing, the machining errors caused by the deformation of the matching of LSFH and cutting tool in machining process can be compensated.

For the convenience of measuring the machining errors, the machining errors in $\mathrm{z}$ direction is the $\mathrm{z}$ coordinate difference between the machined workpiece surface and the machined nominal workpiece surface in each sample points under the workpiece coordinate as shown in Fig. 12 are defined. The $\mathrm{z}$ coordinate values of each sample points are the average value of the four measurements along the $y$ axis direction. The arrangements of each measurement point along the y axis are shown in Fig. 16.

The comparison of machining errors in the $\mathrm{z}$ direction at each sample point of compensation machining and no compensation machining is shown in Fig. 17. It can be found that the machining errors increase with the angle $\varphi$ increase when the error compensation method is not used and the maximum error is $42 \mu \mathrm{m}$. And then, when the compensation method is used, the machining errors in the $\mathrm{z}$ direction are controlled within $10 \mu \mathrm{m}$ and the maximum error is only $9.5 \mu \mathrm{m}$. In addition, the standard deviation of the machining errors with compensation and no compensation is 1.38 and $11.59 \mu \mathrm{m}$, respectively. This suggested that the aforementioned iterative algorithm of tool position point has good robustness.

\section{Conclusions}

Based on analyzing the characteristics of molds and dies characterized by large-scale and deep cavity and machining error, a new machining error compensation method was proposed. A practical example was taken to verify the effectiveness and practicality of this compensation method. The following conclusions were obtained:

(1)The relationship between the deformation of the LSFH-tool system and the surface contour machining error was analyzed. The results showed that the surface contour machining error eventually converted to determine the radial deformation in the horizontal direction and the angle between the normal of machining workpiece surfaces and the cutting tool axis at each nominal cutting tool position point.

(2)The machining error compensation method was proposed and a new algorithm of equilibrium iteration of milling force and deformation was put forward to solve the complexity coupled relationship between the milling force and the deformation of cutting tool system, ultimately to get the compensated machining cutting tool path and achieve offline compensation of machining errors.
(3) Processing example showed that the maximum machining error in $z$ direction reduced from $42 \mu \mathrm{m}$ (uncompensated machining) to $9.5 \mu \mathrm{m}$ (compensated machining) and the machining error is reduced by $77.4 \%$. Furthermore, the standard deviation of machining error in the $z$ direction indicated that the iteration algorithm of error compensation has good robustness.

In high-speed machining of the dies and molds characterized by large-scale and deep cavity, the offline error compensation method proposed in this work can obtain a higher machining dimensional accuracy and surface quality without sacrificing machining efficiency.

\section{Nomenclature}

Symbol, description

$N$, surface normal

$\varphi$, angle between tool axis and surface normal

$e$, horizontal radial deformation

$\rho$, radius of curvature

$T_{R P}$, actual tool position

$T_{N P}$, nominal tool position

$S_{N}$, nominal machining surface

$T_{N}$, nominal tool path

$T_{C}$, compensation too path

$T_{C P}$, compensation tool position

$\varepsilon$, error limitation

$\delta$, machining error

$F_{x}, F_{y}, F_{z}$, milling force

$A_{d}$, nominal cutting depth

$R_{d}$, nominal cutting width

$U_{n}$, actual cutting depth

\section{Competing interests}

The authors declare that they have no competing interests.

\section{Authors' contributions}

ZHM carried out reviewing of literature, guided the entire research work successfully beginning from the research noble idea. LB and ZYH carried out the experiments and tests. PRT made the analysis and vital discussions thoroughly. All authors read and approved the final manuscript.

\section{Acknowledgements}

The authors are grateful to Nature Science Foundation of China (51375418, 51375419, 51275436 and 51475404) and Hunan Province Science Foundation of China (13J J8007).

Received: 13 March 2015 Accepted: 3 July 2015

Published online: 24 July 2015

\section{References}

Arizmendi, M, Fernández, J, López de Lacalle, LN. (2008). Model development for the prediction of surface topography generated by ball-end mills taking into account the tool parallel axis offset. Experimental validation. CIRP Annals Manufacturing Technology, 57(1), 101-104.

Frederic, L, Aurelian, V. \& Bernard, S. (2009). Finite element analysis and contact modeling considerations of interference fits for fretting fatigue strength calculations. Simulation Modelling Practice and Theory, 17(10), 1587-1602. 
Lamikiz, A, López de Lacalle, LN, Ocerin, O, Díez, D, \& Maidagan, E. (2008). The Denavit and Hartenberg approach applied to evaluate the consequences in the tool tip position of geometrical errors in five-axis milling centres. The International Journal of Advanced Manufacturing Technology, 37(1-2), 122-139.

Law, KMY, \& Geddam, A. (2003). Error compensation in the end milling of pockets: methodology. Journal of Materials Processing Technology, 139, 238-244.

Lim, EM, \& Meng, CH. (1995). The prediction of dimensional error for sculptured surface productions using ball end milling process, Part2: Surface generation model and experimental verification. International Journal of machine Tools and Manufacture, 35(8), 1171-1185.

López de Lacalle, LN, Lamikiz, A, Munoa, J, Salgado, MA, \& Sanchez, JA. (2006). Improving the high-speed finishing of forming tools for advanced high-strength steels (AHSS). The International Journal of Advanced Manufacturing Technology, 29, 49-63.

Ryu, SH, Lee, HS, \& Chu, CN. (2003). The form error prediction in side wall machining considering tool deflection. International Journal of machine Tools and Manufacture, 43, 1405-1411.

Salgado, MA, López de Lacalle, LN, \&Lamikiz, A. (2005). Evaluation of the stiffness chain on the deflection of end-mills under cutting forces. International Journal of Machine Tools and Manufacture, 45, 727-739.

Tony, L, \& Schmitz, TL. (2007). Shrink fit tool holder connection stiffness/damping modeling for frequency response prediction in milling. International Journal of Machine Tools and Manufacture, 47(9), 1368-1380.

Zhang, ZW. (2006). High speed, high accuracy shrink-fit holder system. Modern Components, 25(2), 76-78.

Zhang, BL, \& Pan, SS. (1997). Linear motor and its application in ultra-high-speed machine tools. Chinese Mechanical Engineering, 4, 85-88.

Zhang, BL, Yang, QD, \& Chen, CN. (2002). High-speed cutting technology and its application. Beijing, China: Mechanical Industry Press.

Zhou, HM, Wang, CY, Deng, JX, \& Zhao, ZY. (2010). Milling force prediction of the matching of lengthened shrink-fit holder and cutting tool in high speed milling. Mechanical Science and Technology for Aerospace Engineering, 29(4), 504-508.

Zhou, HM, Wang, CY, Deng, JX, \& Peng, RT. (2012). Radial grip rigidity of the matching of lengthened shrink-fit holder and cutter in high-speed milling Chinese Journal of Mechanical Engineering, 25(1), 179-183.

\section{Submit your manuscript to a SpringerOpen ${ }^{\circ}$ journal and benefit from:}

- Convenient online submission

- Rigorous peer review

- Immediate publication on acceptance

- Open access: articles freely available online

- High visibility within the field

- Retaining the copyright to your article

Submit your next manuscript at $>$ springeropen.com 